\title{
Particularidades linguísticas: análise do auto de denúncia de Joana Gil
}

DOI: http://dx.doi.org/10.21165/el.v49i3.2430

\section{Helena de Oliveira Belleza Negro'}

\section{Resumo}

O presente trabalho abordará as análises realizadas em documento do Arquivo da Cúria Metropolitana de São Paulo. O manuscrito é um auto de denúncia contra Joana Gil, que, além do panorama histórico-social, apresenta aspectos linguísticos da escrita do Brasil Colônia, cuja análise pontual verificará o uso e recorrência dos sinais diacríticos agudo ('), til ( ). A partir da análise paleográfica dos escribas Manoel Paes Graçia, Fabio Campos de Abreu Nogueira, Manoel Vaz e de Antonio Xavier de Mattos, buscamos elucidar os fenômenos etimológicos e variações morfológicas presentes no português brasileiro praticado na escrita dos manuscritos eclesiásticos do século XVIII. Como se trata de manuscrito elaborado dentro do âmbito eclesiástico, marcas de uma escrita secular são hipóteses para as práticas dos escribas, bem como a adoção de determinados usos. A partir disso, apresentamos as considerações acerca das tentativas de estabelecimento de formas ou parâmetros de utilização dos diacríticos.

Palavras-chave: filologia; paleografia; diacríticos.

1 Centro Universitário Santanna (UniSant'Anna), São Paulo, São Paulo, Brasil; helena.oliveira@alumni.usp.br; https://orcid.org/0000-0002-8633-7194 


\title{
Linguistic particularities: analysis of Joana Gil's process
}

\begin{abstract}
The purpose of this article is to describe and analyzes a document from the Archives of the Metropolitan Curia of São Paulo. The manuscript is a denunciation against Joana Gil, who, besides the historical-social panorama, presents linguistic aspects of the writing of Brasil, whose punctual analysis will verify the use and recurrence of the acute ('), til ( $\sim$ ) diacritic signs. From the paleographic analysis of the scribes Manoel Paes Graçia and Antonio Xavier de Mattos, we seek to elucidate the etymological phenomena and morphological variations present in Brazilian Portuguese practiced in the writing of eighteenth century ecclesiastical manuscripts. As it is a manuscript elaborated within the ecclesiastical scope, marks of a secular writing fall within the hypotheses for the practices of the scribes, as well as the adoption of certain uses. From this, we present the considerations about the attempts to establish forms or parameters of use of diacritics.
\end{abstract}

Keywords: philology; paleography; diacritics signs.

\section{Introdução}

A presente pesquisa está baseada na análise de manuscritos do Fundo do Arquivo da Cúria Metropolitana de São Paulo, divisão de documentos relacionados às acusações de feitiçaria e atualmente pesquisado pelo Grupo de Estudos Bruxas Paulistas: Edição Filológica de Documentação sobre Feitiçaria, da Faculdade de Filosofia, Letras e Ciências Humanas da Universidade de São Paulo - FFLCH - USP, que tem como objetivo a realização da edição semidiplomática e análise linguística e filológica do corpus, restabelecendo a história social e sua representatividade linguística.

O processo de Joana Gil, foco deste artigo, assim como os outros que fazem parte do mesmo fundo composto por 12 processos, foi instaurado em Mogi Mirim e apresenta como rés Joana Gil e Lucrécia Dias Gil. Ambas afirmaram, segundo a análise do material, presenciarem a imagem de Sant'Anna chorar lágrimas de sangue, além de afirmarem prever o futuro e verem demônios. As notícias sobre esses acontecimentos se espalharam pela vila e a idolatria à Joana foi o ponto nevrálgico para a instauração do auto de denúncia emitido pelo Tribunal do Santo Ofício com a acusação de falsa santidade e idolatria.

Todos os relatos foram registrados por escrivães, cuja função era captar os relatos dos inquiridos pela Justiça Eclesiástica. Essa afirmação é possível devido à identificação das marcas documentais presentes nas assinaturas dos manuscritos. Os punhos, denominação de autoria das escritas, pertencem a Manoel Paez Graçia, escrivão do auditório eclesiástico, a Antonio Xavier de Mattos, reverendo vigário de Mogi Mirim, a Flavio Campos de Abreu Nogueyra, escrivão, e a Manoel Vaz, reverendo vigário da comarca de São Paulo. 
Serão esses depoimentos o foco das análises linguísticas, atentando-se para os usos dos sinais gráficos ou sinais diacríticos, em especial, o agudo e o til. Tais análises, contudo, não serão realizadas sem antes verificar-se o traçado de cada escriba com o auxílio da edição semidiplomática e de análise paleográfıca.

Literatura auxiliar será utilizada para que a contextualização dos usos seja feita à luz de pesquisas recentes, sem deixar de lado as contextualizações que envolvem a evolução das ideias linguísticas e da história da escrita, no levantamento das hipóteses para os dados encontrados.

\title{
Aspectos filológicos
}

O estudo filológico apresenta, dentre as suas definições, o estudo geral de um texto, trazendo ao presente os múltiplos significados que este contém: desde o restabelecimento da história social de uma época até o estudo linguístico de sua escrita, com o uso de ciências auxiliares como a História, a Sociologia, a Paleografia e a Codicologia.

Não há como estabelecer os dados encontrados e detalhados nos próximos subcapítulos sem realizar algumas observações prévias, sendo a Codicologia uma das ciências auxiliares, que possibilitarão essa análise inicial. Assim, a partir da observação dos aspectos codicológicos, será realizada a contextualização do processo de guarda e características do suporte material.

\section{Análise codicológica}

Cambraia (2005, p. 26) define:

\begin{abstract}
A codicologia consiste basicamente no estudo da técnica do livro manuscrito (i. é, do códice). [...] Lemaire (1989:3) postula dever a codicologia fixar-se sobretudo em compreender os diversos aspectos da confecção material primitiva do códice. Para o crítico textual, a codicologia é de grande relevância, pois fornece informações que permitem compreender algumas das razões pelas quais os textos se modificam no processo de transmissão.
\end{abstract}

Partindo da definição proposta por Lemaire e apropriada por Cambraia, a verificação dos dados referentes ao suporte material desse manuscrito foi realizada para identificar o procedimento do Arquivo.

O projeto está estruturado na avaliação de processos inseridos na subdivisão "feitiçaria" e a designação dada aos autos é parte da análise histórico-social dos manuscritos. 
A figura 1 ilustra as características da capa que envolve o processo. Pode-se identificar no canto superior direito o ano da sua instauração, no canto superior esquerdo, o fundo (crime) e as alíneas 1 e 2, em frente à designação do fundo, apontam o motivo (idolatria, falsa santidade). Abaixo dessas informações, há os nomes e o estado civil das rés; após, segue-se a localização e, na última parte da folha, figura um resumo do ocorrido. No rodapé consta uma data, que remete à leitura e catalogação dos dados.

Figura 1. Capa de guarda e identificação do processo de Joana Gil elaborada por terceiros

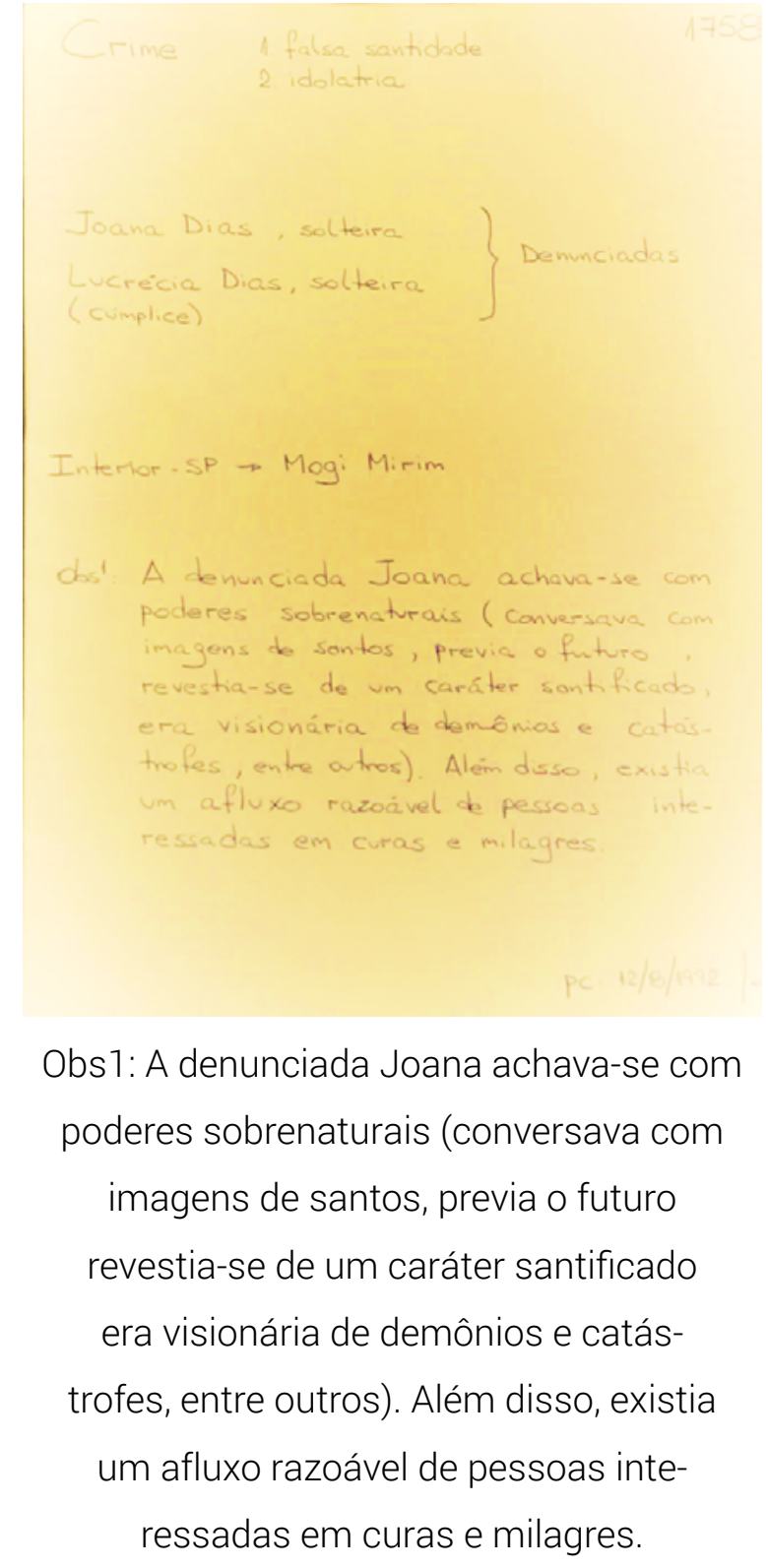

Fonte: Arquivo público da Cúria Metropolitana de São Paulo 
O processo de Joana Gil está classificado como crime. As folhas sem pauta nas quais o documento foi escrito foram submetidas a um procedimento de restauro que permite identificar as marcas deixadas pelas traças que, embora tenham corroído substancialmente o manuscrito, deixaram preservadas a parte escrita, motivo pelo qual não se inviabiliza a leitura.

As intervenções de terceiros e marcações posteriores são raras e toda a escrita está apoiada nos relatos e despachos escritos pelos quatro escribas, responsáveis pela captação dos depoimentos e emissão de despachos.

Como todos os fac-símiles presentes no arquivo, o auto é envolto em uma folha de papel almaço, sem pautas, com um breve resumo sobre o documento, informando o ano, motivo do processo. Essa identificação é de responsabilidade do gestor do arquivo, senhor Jair Mongeli, profundo conhecedor dos documentos.

Todos os documentos são arquivados em pastas de plástico polionda, as quais contêm identificação específica, com a datação por século e a identificação do tipo processual que faz parte de seu conteúdo.

Os punhos, em sua maioria, não apresentam obstáculo à leitura, com exceção do punho C, cuja caligrafia apresentou maiores dificuldades de decifração.

\section{Análise paleográfica}

Conforme a definição de Mendes (2008, p. 16), a paleografia consiste na "Arte de ler o documento antigo. Estariam englobados nessa atividade a capacidade de superar as vicissitudes sofridas pela escrita, a interpretação desta, o conhecimento de uma origem, a evolução e a época".

Partindo disso, as análises realizadas no auto de denúncia de Joana Gil possibilitaram identificar e estabelecer alguns parâmetros. O documento é composto por treze fólios, manuscritos com tinta avermelhada, provavelmente ferrogálica.

O documento manteve os padrões estabelecidos para a escrita processual, seguindo os preceitos das Ordenações Filipinas, quanto ao formato da captação das informações das testemunhas e de direcionamento do auto, para posterior envio a Lisboa, trâmite comum realizado para os documentos do Tribunal do Santo Ofício. Essas informações foram identificadas no decorrer da transcrição, pois é possível ler o despacho realizado à comarca de São Paulo. 
A existência de escritas feitas por diferentes autores ${ }^{2}$ demonstra várias aplicações para a língua em um contexto controlado e normatizado para os procedimentos de captação de testemunho, tendo em vista que os depoimentos seguem um formato preestabelecido e a transposição dos testemunhos é realizada em tempo real, ou seja, o escriba deve apresentar familiaridade com as particularidades linguísticas, pois não dispunha tempo de reação ou de pesquisa para a reescrita de determinados termos.

Ao realizar-se a transcrição do manuscrito, fazendo-se uso da edição semidiplomática ${ }^{3}$, identificou-se o uso distinto de variedades lexicais, o que demonstra a ausência de regularidade ou de sistematização da língua escrita, principalmente, no que se refere ao uso do til em final de palavra.

A edição também prevê a identificação das características do traçado dos punhos, mantendo as leituras do original, sem que haja modernização da escrita. Diante disso, os diacríticos utilizados pelos escribas foram mantidos.

Para melhor detalhar os autores e os usos que adotaram, elaborou-se o quadro 1, em que os punhos foram identificados e renomeados, para proporcionar praticidade às análises que serão realizadas.

Quadro 1. Características dos punhos

\begin{tabular}{|c|c|c|c|}
\hline $\begin{array}{c}\text { Punho 1 } \\
\text { Manoel Paez Graçia }\end{array}$ & $\begin{array}{c}\text { Punho 2 } \\
\text { Antonio Xavier de } \\
\text { Mattos }\end{array}$ & $\begin{array}{c}\text { Punho 3 } \\
\text { Fabio Campos de } \\
\text { Abreu Nogueira }\end{array}$ & $\begin{array}{c}\text { Punho 4 } \\
\text { Manoel Joz }\end{array}$ \\
\hline & & & \\
\hline $\begin{array}{c}<\text { saõs } \\
\text { (verbo) }\end{array}$ & $\begin{array}{c}<\text { saõs } \\
\text { (verbo) }\end{array}$ & $\begin{array}{c}<\text { saõs } \\
\text { (verbo) }\end{array}$ & $\begin{array}{c}<\text { Remettaõ } \\
\text { (verbo) }\end{array}$ \\
\hline
\end{tabular}

Fonte: Elaboração própria

2 No decorrer do artigo também será encontrada a denominação "punhos" para fazer referência aos autores ou escribas.

3 A edição semidiplomática consiste na reprodução do manuscrito, com interferências médias, conferindo ao texto uma leitura apreensível para as pessoas que não compreenderiam o texto original. Nesse tipo de edição, os sinais abreviativos são desenvolvidos, as inserções ou supressões de elementos de terceiros são delimitadas e as características linguísticas mantidas, sendo de fundamental importância para estudos linguísticos posteriores. 
A escolha desses vocábulos deve-se à similaridade no uso do diacrítico til, uma vez que todos os escribas grafaram com o ditongo nasal as respectivas palavras.

Percebem-se os diferentes traçados dos sinais, que, em todos os casos, são posicionados sobre o ditongo nasal, embora alternadamente, ora sobre $0<0>$ como fazem os punhos 1 , 3 e 4, ou entre os dois, como realiza o punho 2.

Na realização dessas palavras não foi encontrada variação de escrita para o ditongo nasal no que se refere ao uso da variedade <am>. Quanto à realização e características do traçado dos punhos, identificam-se diferentes formatos para o mesmo sinal gráfico, o que pode levar à inferência de que o diacrítico seja diverso a sua função apresentada.

Diante disso, não se descarta o uso do agudo nessa posição, mas atribui-se a função adequada ao seu uso. Corroboram com o uso do agudo gramáticos setecentistas, devido à adoção de meios didáticos para o ensino-aprendizagem da identificação da tonicidade.

Infelizmente, o punho 4 apresenta poucas linhas escritas, insuficientes para que fosse realizada uma análise mais apurada de suas aplicações, mas o bastante para o levantamento de algumas hipóteses que serão apresentadas a seguir.

\section{Aspectos gerais dos documentos}

O manuscrito está inserido no contexto jurídico-eclesiástico. Caracteriza-se por um protocolo formulaico em que a escrita segue as normativas dos Regimentos Processuais, como as Ordenações Filipinas, ou ainda, o Supremo Tribunal da Inquisição. Ambos determinam o rito processual e como essas partes serão descritas no auto. 
Figura 2. Trecho do auto de Joana Gil elaborado pelo punho 4

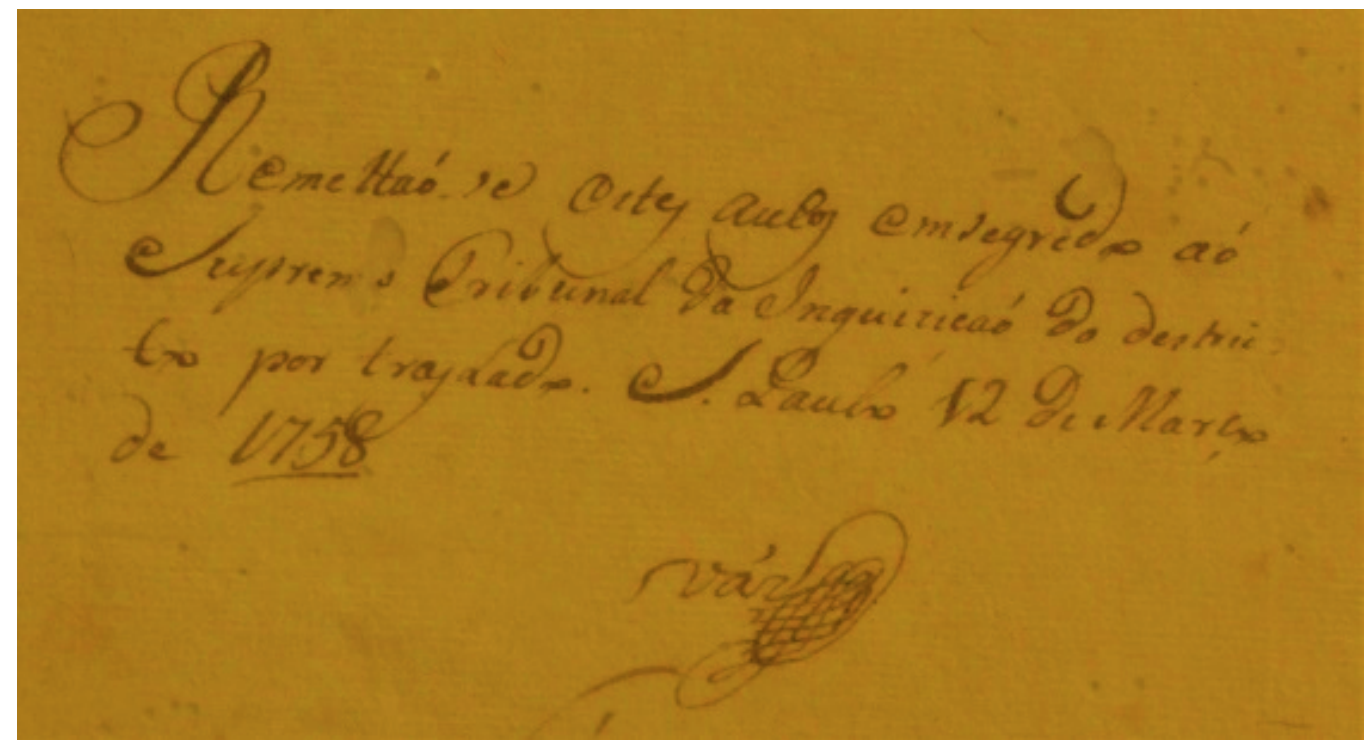

Remettaó-se estes autos emsegredo aó

Supremo Tribunal dalnquiziçaó do destric

to por traslado. Saõ Paulo 12 de Março

de 1758.

Váz[rubrica]

Fonte: Manuscrito do acervo do Arquivo da Cúria Metropolitana de São Paulo

Além desse fator, há outro ponto a ser considerado que é o tratamento dado a um documento produzido no âmbito eclesiástico. Esses processos seguem as premissas de uma entidade religiosa, que, no caso, é o Supremo Tribunal da Inquisição, como menciona o próprio fac-símile, em último despacho escrito pelo punho 4.

O auto, de maneira geral, apresenta grande diversidade de marcas linguísticas associadas aos períodos fonéticos e pseudoetimológicos da língua, segundo classificação de Coutinho (1976). No entanto, não há unanimidade nas orientações e classificações, tendo em vista que tais marcas estão inseridas em períodos anteriores à escrita documental. As ocorrências que podem ser apontadas em $\langle$ oyto $\rangle$, <janeyro $\rangle$, $\langle$ bayrro $\rangle$, <heroycas $\rangle$, $<$ deytada $>$, < noyte $>$ e <cazeyros $>$ utilizadas pelo escriba $1 ;<$ conceyto $>,<$ cheyro $>$, < direyta $>$, $<$ caveyra $>$, <oyto $>$ e $<$ bayxo $>$ empregadas pelo escriba 2; em <bayrro $>$, <caveyras $>$, pelo punho 3 e <oytos, pelo punho 4.

Mattos e Silva (2006) apresenta a diversidade das aplicações dos ditongos decrescentes para chegarmos a essas considerações. No português arcaico, o uso do <y> era recorrente no lugar da vogal anterior para designar a semivogal nos ditongos decrescentes. 
[...] até o final do período arcaico, palavras como essas apareciam grafadas não com grafemas próprios às semivogais (i, y, h para a semivogal anterior /y/ e u para a posterior /w/), mas com e ou o: cruees, soes, ceo, o que indica que antes de se tornarem semivogais esses elementos eram vogais e até se ditongarem constituíam sequências vocálicas em hiato [...]

As aplicações de $<y>$ em lugar de ditongo crescente remetem à origem dos autos, uma vez que o ambiente eclesiástico mantém a tradição vernacular até os dias atuais e esses usos remetem ao período arcaico da língua. Há de se levar em consideração também que a Igreja, até meados do século XVIII, concentrava a educação de toda a colônia, fato que justifica a escrita documental. Verney (1746) apresenta o uso do $<y>$, embora julgando-o desnecessário e sugerindo $0<i>$ em seu lugar, pois tem a mesma função da vogal, mas a primeira remete às palavras de origem grega, apesar das ressalvas quanto a essa afirmativa.

Além desses usos, observou-se a escrita de consoantes duplicadas, que remete à função pseudoetimológica da língua. Exemplos podem ser detectados em <elle $>$, <catholicos, $<$ condemnar $>$ e $<$ facto $>$ realizadas pelo punho 1, e do uso de $<\mathrm{Z}>$ em lugar de $<$ S $>$ como em <freguezia $>$, <cazados $>$, <cazo $>$ e $<$ desacato $>$, realizadas pelo punho 2. Algumas destas já haviam sido cristalizadas pelos dicionários contemporâneos à escrita como o Vocabulário Portuguez e Latino, de Bluteau, com a apresentação das duplicidades consonantais em $<$ elle $>$ e $<$ facto $>$.

O uso de $<z>$ em lugar de $<$ s $>$ e a adoção de $<y>$ em ditongo crescente remetem ao período fonético, enquanto o uso de consoantes mudas, com motivação etimológica, ocorre desde o século XVI, numa tentativa de resgatar o período clássico como símbolo de cultura.

Essas análises possibilitam o levantamento de hipóteses para a adoção de determinados usos diacríticos na escrita eclesiástica, a saber: i) escrita baseada em modelo antigo, em que as premissas arcaicas e pseudoetimológicas faziam frente ao modo como se operava a comunicação eclesiástica; ii) esse modelo explica os usos de til em detrimento do $<m>$ nos ditongos nasais, assim como o uso das nasais $<m>$ em lugar de til. Nesse caso, remete-se a uma escrita latina, característica do latim pré-literário (NUNES, 1945), ratificando o apontamento de Oliveira $(1536$, p. 8) que afirmou que "he. m. nem. n. como nos escreuemos ora hũa dellas: ora outra imitando os latinos".

\section{Análise das incidências, comparações e conjecturas}

Diacríticos são sinais gráficos que conferem novo valor fonético e/ou fonológico a uma letra (AULETE, 2018). Ao analisar a regularidade dos usos desses sinais pelos quatro 
escribas, realizou-se o levantamento da incidência com que os sinais gráfıcos apareciam e quais palavras que os recebiam, delimitando a análise ao til ( ) e ao agudo (').

Gráfico 1. Vocábulos por tipo de diacrítico

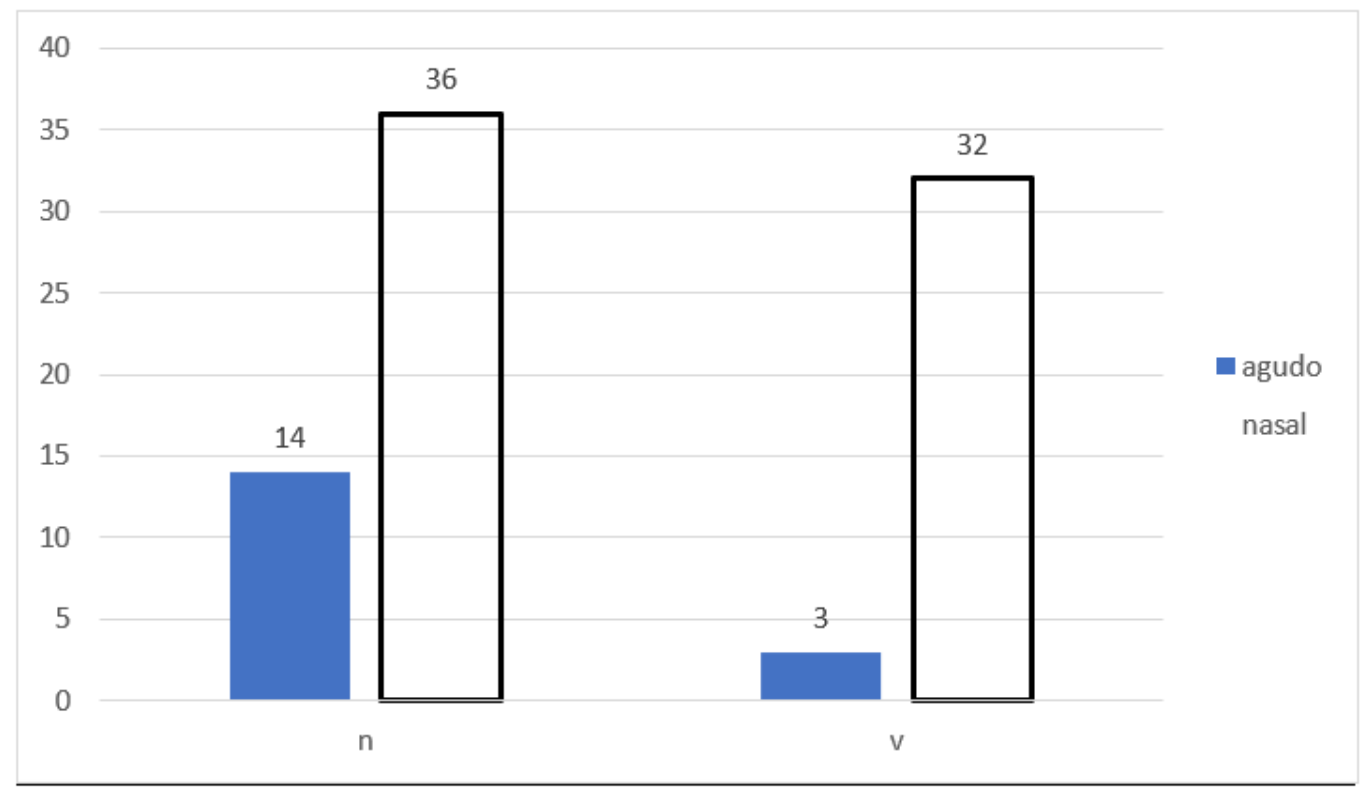

Fonte: Produção do autor a partir dos dados retirados do auto de denúncia de Joana Gil

Observa-se que as colunas de cor sólida escura se destinam à representação do uso do agudo como forma de demonstração de tonicidade. O agudo é muito mais usual nos nomes do que nos verbos, pois para os verbos a marca de nasalização é realizada com o til.

A esse respeito, Verney (1746) e Lobato (1770) já apontavam para a função do agudo como direcionamento de tonicidade silábica e distinção de tempo verbal. Os casos em que o diacrítico é apresentado nos verbos ocorrem em <hé> e <há>. Segundo Lobato (1770, p. 176),

Ás vezes sobre a vogal da syllaba longa se põem o seguinte final, (') a que chamão accento agudo; ou este, $\left({ }^{\wedge}\right)$ a que chamão accento circumflexo. O primeiro serve para denotar, que se deve pronunciar a vogal, fazendo hum som aberto, como se vê na vogal o da primeira syllaba do verbo Gósto. O segundo denota, que se deve pronunciar a vogal, fazendo hum som fechado, como se vê na vogal o da primeira syllaba do nome Gôsto. 
Quanto à colocação do diacrítico sobre o ditongo nasal, Belleza Negro (2017) afırma que os diacríticos podem ser utilizados para representar uma função diferente daquela a que se propõem. Exemplo disso é o uso do agudo em ditongos nasais para representação da nasalidade, como feito pelo punho 4, exemplificado no trecho da figura 2.

A possibilidade de facilitação e democratização da escrita ganhou força no século XVIII. Além do Novo Método de Estudar, de Verney (1746), a Nova escola para aprender a ler, escrever, e contar, de Figueiredo (1722) deixava explícita a sugestão às crianças que estavam aprendendo, sugerindo o uso do agudo para marcação de tonicidade, uniformizando o modelo de escrita e resumindo a um único uso a variedade de sinais gráficos presentes até aquele momento.

Estabelecer regularidade ou similaridade no uso dos sinais gráficos tem sido difícil tarefa, tendo em vista as diversas ocorrências localizadas nos documentos manuscritos setecentistas. O auto de Joana Gil não se mostra diferente ao apresentar algumas possibilidades de aplicação do til, sempre posto sobre o ditongo nasal. Nesse caso algumas hipóteses podem ser defendidas diante dos usos adotados pelos escribas e da origem documental.

O gráfico 2 apresenta esse mapeamento, em que relacionamos a mesma palavra e as diferentes formas como foram grafadas. Verifica-se que um mesmo punho utiliza formas distintas para representar a nasalidade como ocorre em <Sebastiam/ Sebastiaõ $>$, punho 1. Procedimento similar também pôde ser identificado nas aplicações desse escriba que alterna o uso do sinal gráfico para representar a nasalidade em <hua>. Embora não esteja representado no gráfico, também foram encontradas ocorrências em que o final <ões> foi apresentado sem o uso do til e em seu lugar <oins>, como <invensoins> e <ilusoins>, realizadas pelo punho 1 .

Atribuir o uso de diacríticos a um processo de estilo de escrita conflita com alguns preceitos difundidos no século XVIII, em especial, ao procedimento de ensino, quando se identifica a existência de manuais de escrita que sugeriam o uso de um sinal em detrimento do outro para representar a tonicidade em vogais tônicas, ou ainda, a uniformização da escrita convencionando o uso em uma única posição. É o que aponta Figueiredo (1722, p. 65):

O agudo levanta mais a voz, o grave há o que abayxa, o circumflexo participa de ambos; porém para meninos me parece acertado usarem só do agudo, \& muytos escritores na língua Portuguesa só dele usão nas palavras.

O verbo Pôr, se acentua, mas não a proposição, por, \& assim diremos; Foy-se pôr ao Sol, por causa do frio: este acentos no verbo pôr, há de ser precisamente 
circumflexo, porque o agudo levanta mais a voz. Também se acentua o verbo Esta, por se distinguir do nome, esta, como: Esta regra está certa. Nesta fòrma se devem instruir os principiantes, dandolhe noticia de outras mais palavras, que se equivocão na escritura, \& se conhecem pela diversidade da pronunciação, como também os futuros, que todos se accentuaõ na ultima vogal.

Gráfico 2. Variação de usos dos diacríticos e punhos diferentes

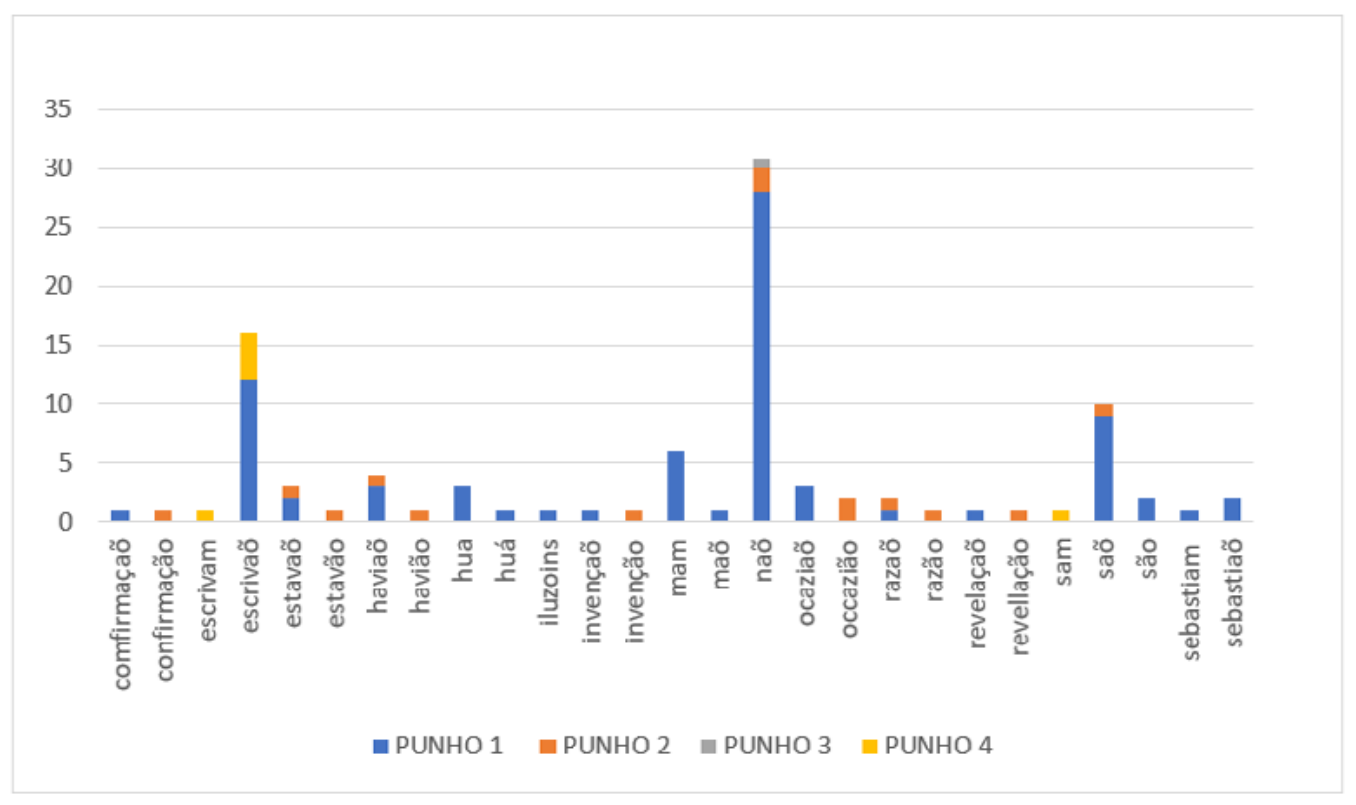

Fonte: Produção do autor a partir dos dados do auto de denúncia de Joana Gil

Materiais didáticos, voltados à concepção dos manuais e à análise dos livros dedicados ao ensino das primeiras letras, foram analisados por Vieira (2017), Duarte, Outeirinho e Ponce de Leon (2014) e ratificam o uso didático dos sinais gráficos. Diferentemente disso, as gramáticas e ortografias do XVII e XVIII apresentam abordagens sistematizadas da existência dos sinais, buscando justificar suas aplicações, mas foi a partir do século XVIII que esse processo passa para uma consolidação inicial, com Verney (1746).

Dentre os escribas é recorrente a variação de uso e aplicação do diacrítico nos ditongos nasais. Em análise paleográfica, podemos identificar e concluir em duas hipóteses:

(1) aplicação usual para determinar que existe nasalidade. Diante disso, o local de aposição e a forma do diacrítico (circunflexo, til ou agudo) não faz diferença, mas sua intenção sim.

(2) verificação etimológica para estabelecimento de correlação do uso do acento gráfico em uma das vogais; 
Considerando a segunda hipótese, a etimologia pode oferecer-nos subsídios para explicar determinados usos, mas nem sempre poderá abarcar todos.

O uso de <oins >, em <iluzoins>, e <oens >, em <invensoens>, por exemplo, empregado pelo punho três, embora não esteja presente no gráfico 2, mostra marca fonética na escrita, pois a nasalização se dá com o uso do <n> após o ditongo. No entanto, ao usar as mesmas palavras no singular, é necessário adotar o ditongo nasal /aw/, mas há casos em que o uso do diacrítico til e da nasal $<m>$ ao final da sílaba são utilizadas. Mattos e Silva (2007) apresenta o percurso do ditongo /ow/<0̃<one/unt e a forma latina é a que permanece na escrita de <iluzoins $>$ e <invensoins $>$.

Verifica-se que um mesmo escriba fez mais de um uso, quer aplicando, quer não aplicando o diacrítico, ora sobre a primeira, ora sobre a segunda vogal. Há também uso do <m> em detrimento do til. Essa utilização foi realizada pelos punhos 1 e 4, em <escrivam> e $<$ sams.

Diante dessas ocorrências - alternância de aposição do sinal gráfico podemos remeter a Figueiredo (1722) que em seu Manual setecentista apresentava possibilidades aos iniciantes à escrita para que o uso fosse facilitado.

Se o uso dos sinais gráficos de nasalidade e tonicidade eram "facilitados", como sugere Figueiredo (1722) pode-se empreender que estão atrelados à agilidade do punho e característica do traçado. A alternância do uso <ão>/<aõ > fornece-nos essa possibilidade, no entanto, o uso de <am> em detrimento de <ão>/<aõ > para os vocábulos <escrivaõ $>$, $<$ mão $>$ e < Sebastião > remetem à "confusão" relatada por Verney (1746), ou seja, o uso de $<m>$ e <ão/aõ > atuam conjuntamente, no córpus, e tais aplicações são adotadas pelos mesmos escribas, conduzidos a um modelo de escrita eclesiástica.

Identifica-se esse viés após levantamento vocabular e identificação das ocorrências de $<y>$ em substituição ao <i> em ditongos, ou ainda, no uso de $<m>$ em detrimento do til, nos ditongos nasais.

Ao identificarmos o uso do $<\mathrm{m}>$ em detrimento do til, remete-se ao uso latino, ou seja, a consoante nasal em lugar da abreviatura.

\section{Considerações finais}

A partir da análise desse documento, identificamos similaridades com outro manuscrito, o processo-crime de devassa de Thereza Leite, pertencente ao mesmo fundo de pesquisa e da mesma época. Essa característica e a distinção entre os escribas que realizaram ambos os documentos fortalecem a hipótese de uma escrita que tinha como intenção a 
proximidade da escrita clássica, padrão a ser seguido pela tradição e conservação aos preceitos clássicos.

Apesar da inexistência de um manual ou documento oficial que corrobore a hipótese, localizaram-se mais de um elemento que remete a essa prática como o uso do $<y>$ como semivogal, o <am> como marca de nasalidade, ou <oins $>$ em detrimento do til no ditongo nasal.

Diante das ocorrências apresentadas e das aplicações realizadas para os usos dos diacríticos agudo e til, identificou-se a utilização voltada ao modelo clássico de escrita, atribuída à origem documental - a Igreja. As recorrências, não apenas aos usos dos diacríticos, em especial, a retomada do <m> em detrimento de <ão/aõ >, ou ainda, o uso de <oins > por <ões > remetem a um modelo vocabular latino de emprego das consoantes nasais. Corroboram com essa análise as outras escolhas linguísticas adotadas pelos escribas, como as consoantes surdas, forma de remeter, ainda que equivocadamente, ao modelo clássico.

Oliveira (1536) e Belleza Negro (2017) já mencionaram esse uso, entendendo que o til, apesar de não servir como sinal abreviativo pelos latinos, passou a sê-lo pelos portugueses. Dessa forma, apresenta as formas de representação nasal e ratifica a adoção do til na escrita portuguesa.

Como afırma Certeau (2011, p. 202) "o discurso constitui um espaço simbólico no que se traçam diferenças existenciais. Aqui o símbolo é a expressão". Apesar de o autor fazer referência à micro-história, não se pode deixar de atrelar o auto de denúncia de Joana Gil ao contexto secular das instituições religiosas. Coaduna-se também à função transcendente da filologia, em que o resgate histórico é o fim para o restabelecimento do percurso social apresentado no manuscrito. A expressão, referenciada pelo autor, pode ser identificada no manuscrito, pois a forma de escrita de uma instituição ou seu modelo existencial deve-se à tradição e à necessidade de consolidação de características específicas, que a identifica e diferencia dentre as demais, mantendo sua singularidade através dos tempos.

\section{REFERÊNCIAS}

AULETE, C. Dicionário de língua portuguesa digital. Disponível em http://aulete.com.br/. Acesso em: 31 ago.2019.

BELLEZA NEGRO, H. de O. Usos e normas: estudo diacrônico sobre os usos dos diacríticos na língua portuguesa do Brasil. 2017. Tese (Doutorado em Filologia e Língua Portuguesa) - Faculdade de Filosofia, Letras e Ciências Humanas, Universidade de São Paulo, São Paulo, 2017. Disponível em: http://www.teses.usp.br/teses/ disponiveis/8/8142/tde-26062017-112626/pt-br.php. Acesso em: 31 ago. 2019. 
CAMBRAIA, C. N. Introdução à Crítica textual. São Paulo: Martins Fontes, 2005.

CERTEAU, M. A escrita da história. Rio de Janeiro: ABDR, 2011.

COUTINHO, I. de L. Gramática histórica. Rio de Janeiro: Editora ao Livro Técnico, 2005.

DUARTE, S.; OUTEIRINHO, F.; PONCE DE LEON. Dos autores aos métodos de ensino das línguas e literaturas estrangeira em Portugal. Porto: CLUP, 2014.

FIGUEIREDO, M. de A. Nova escola para aprender a ler, escrever, e contar oferecida a augusta majestade D. João V, rey de Portugal. Lisboa: Officina de Bernardo da Costa de Carvalho. 1722. Disponível em: http://purl.pt/107. Acesso em: 25 out. 2015.

MATTOS e SILVA, R. V. O português arcaico: fonologia, morfologia e sintaxe. São Paulo: Editora Contexto, 2006.

NUNES, J. J. Compendio de gramática histórica portuguesa. Lisboa: Livraria Clássica Editora, 1945. p. 188-190.

TEYSSIER, P. História da língua portuguesa. São Paulo: Martins Fontes. 2007.

VERNEY, L. A. Verdadeiro método de estudar para ser útil à república e à igreja: proporcionado ao estilo, e necessidade de Portugal. Exposto em varias cartas, escritas poloto R. P. ***Barbadinho da Congregasam de Italia, ao R. P *** Doutor na Universidade de Coimbra. Valensa: Oficina de Antonio Balle. 1746. Disponível em http://purl.pt/118. Acesso em: 01 maio 2016.

VIEIRA, Z. P. P. Cartilhas de alfabetização no Brasil: um estudo sobre trajetória e memória de ensino e aprendizagem da língua escrita. 2017. Tese (Doutorado em Memória: Linguagem e Sociedade) - Programa de Pós-graduação em Memória: Linguagem e Sociedade, Universidade Estadual do Sudoeste da Bahia, Bahia. Disponível em: http:// www2.uesb.br/ppg/ppgmls/wp-content/uploads/2017/09/Tese-Zeneide-Paiva-PereiraVieira.pdf. Acesso em: 15 ago. 2019. 